\title{
Intelligent Prediction of Fault Severity of Tractor's Gearbox by Time-domain and Frequency-domain (FFT phase angle and PSD) Statistics Analysis and ANFIS
}

\author{
Mostafa Bahrami $^{1 *}$, Hossein Javadikia ${ }^{1}$, Ebrahim Ebrahimi \\ ${ }^{1}$ Department of Mechanical Engineering of Agricultural Machinery, Faculty of Agriculture, \\ Razi University, Kermanshah, Iran \\ ${ }^{2}$ Department of Mechanical Engineering, Faculty of Engineering, \\ Kermanshah Branch Islamic Azad University, Kermanshah, Iran \\ *Corresponding author: mostafa.bahrami.2@gmail.com
}

\begin{abstract}
This study presents an approach to intelligent fault prediction based on time-domain and frequency-domain (FFT phase angle and PSD) statistical analysis, Principal component analysis (PCA) and adaptive Neuro-fuzzy inference system (ANFIS). After vibration data acquisition, the approach consists of three stages is conducted. First, different features, including time-domain statistical characteristics, and frequency-domain statistical characteristics are extracted to get more fault detection information. Second, three components by a principal component analysis are obtained from the original feature set. Finally, these three components are inputted into ANFIS for a development model of identifying different abnormal cases. The proposed approach is applied to fault diagnosis of gearbox's number one gear of MF285 tractor, and the testing results show that the proposed model can reliably predict different fault categories and severities.
\end{abstract}

Keywords: fault severity prediction, gearbox, FFT, PSD, ANFIS

\section{INTRODUCTION}

Commonly, a series of gears are used for power transmission from the engine to the drive wheels of the tractor. These gears are applied to reduce speed and increase of torque for translation of power to the drive wheels. Gearbox performs the following works. A) Transfer of the speed and torque of an engine for required speed and torque to turn the wheels. B) Reverse the tractor output shaft of the gearbox to reverse of tractor movement. C) Don't transfer of a move to wheels without the need to turn off the engine or clutch pedal pressed continuously. D) It also turns another drive shaft that called power take off (PTO).

Gearbox is one of the most important parts in rotating machines. It applied to quickly power transmission from one shaft to another shaft. If defects do occur during the work, damage can be got into other components (Loutrid, 2008). Therefore, early detection and diagnosis of fault is a very important (Lei et al., 2009).

Various methods for gearbox fault diagnosis are presented. One of the most basic methods is based on vibration fault diagnosis. Due to measure vibration is easy (Halima et al., 2008; Jafarizadeh et al., 2008; Zuo, et al., 2005).

More than half of the fault severities in gear transmission is the gear's deficiency (Yesilyurt, 2004), in this paper, faults of gear's number one of MF285 tractor are considered.

After the feature extraction for automatic fault diagnosis system are completing, classifications are used. The automatic fault detection system can reduce the need for skilled operators and increase the speed and reliability of detection. Intelligent computing techniques are used to classify different faults. It can by using techniques such as artificial neural networks. (Bangalore and Tjernberg, 2015; Ali et al.,2015; Ahmed et al.,2015, Jia et al.,2015), Support vector machines (Jedliński and Jonak, 2015; Liu et al., 2016; Li et al., 2016; Mustafa et al., 2016), Fuzzy logic (Dehghani et al., 2016: Adhikari et al., 2016) Adaptive Neuro fuzzy inference system.( Milovančević et al., 2016; Moosavian et al.,2015; Soualhi et al.,2014 ).

Previous researches are done to determine or predict of the fault severity in addition to determining the fault type too (Sharma et al., 2016; Kaplan et al., 2015).

Artificial Intelligence techniques such as artificial neural networks and fuzzy logic are used successfully for the intelligence detection of fault in rotating machines. Adaptive Neru fuzzy inference system is a hybrid model which it combines the neural network's ability to adapt and fuzzy logic qualitative (Jang, 1993). Using mathematical properties of artificial neural network in the fuzzy knowledge base system that follows approximate of the human information processing method. ANFIS successful implementation of the common faults in intelligent diagnosis has been reported (Lou and Loparo, 2004; Ye et al., 2006).

Although a little research has been done to detect faults in tractor gearbox (Heidarbeigi et al., 2010; Ebrahimi et 
al., 2013) so far nothing has been done to predict the severity of the fault of the gearbox.

In this paper, fault severity predict of a number one gear of MF285 tractors was considered. After extracting features in time and frequency domains (FFT phase angle and PSD). Three factors extracted by PCA as the
ANFIS inputs. This system predicts the faults of the gear successfully. The first part of this article explains how to perform the experiment. ANFIS and PCA then briefly described and the results are presented and discussed. The flow chart of the fault diagnostic system in this study is shown in Figure 1.

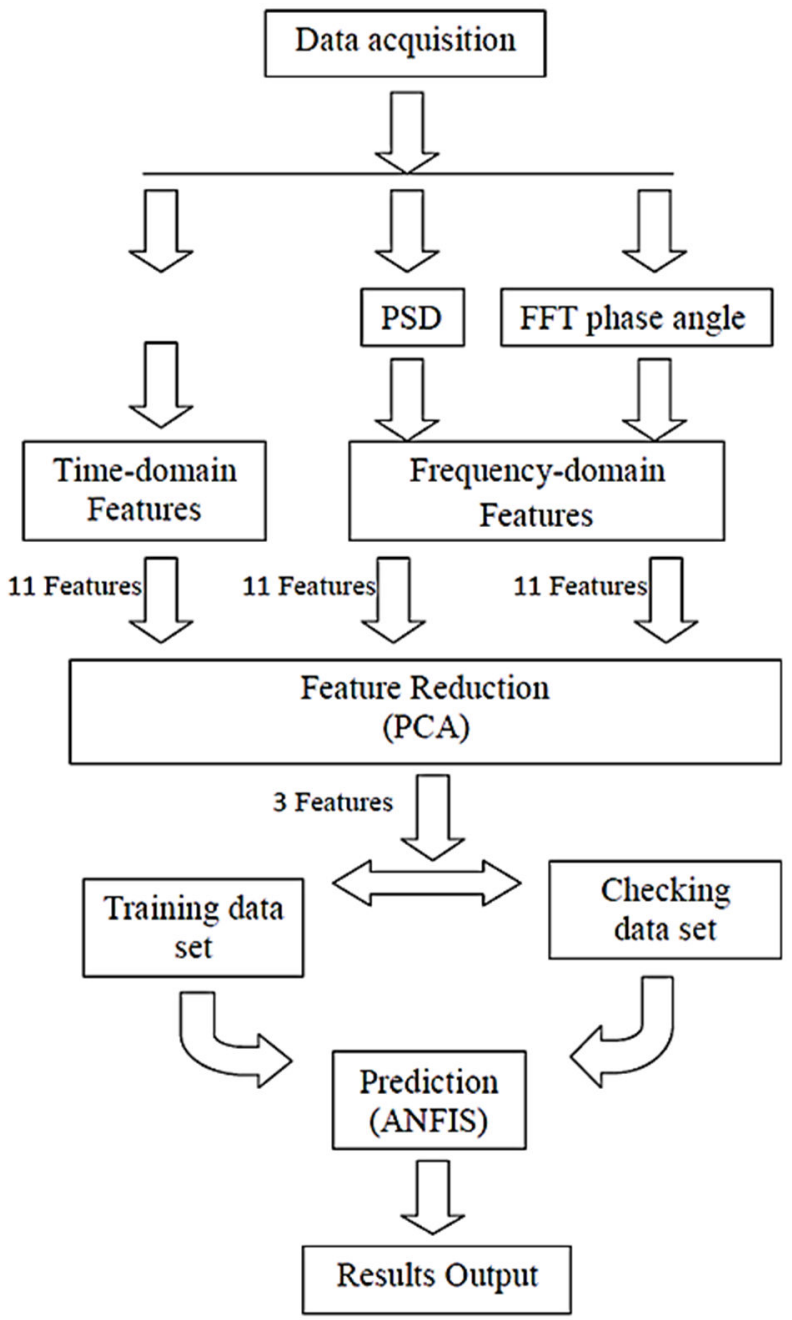

Figure 1. Fault prediction Flowchart.

\section{MATERIALS AND METHOD}

\section{Experimental System Description}

Gear number's one of transmission gears, Massey Ferguson 285 tractor has 44 teeth. The gear is located on an experimental platform for data capture. The gear of MF285 clutch axle and transmission gear is jointed normally. For each of axles, two bearings are used as a fulcrum. Hence brings simulates the real situation was mounted on the chassis in a laboratory. The data set was recorded in healthy condition; gear with broken teeth and the abrade teeth.
In any case, the speeds of 1000, 1500 and 2000 was performed. Iteration rate for each case was 130. Data were recorded for each sample. Single-phase electric motor YCA90S-2 models for input shaft to provide rotary motion for data capture was used during the tests. In this study of a piezoelectric accelerometer model VMI Ltd, VMI-102 Sweden is applied to measuring vibration severity. 
The accelerometer has an analog output, therefore cannot be directly entered into the computer system. Generated analog signals from the accelerometer output must be converted to digital signals before entered into the computer system. For this purpose the analyzer device APC-40, APC Ltd, Korea was used which has the ability to data capture $40 \mathrm{MHz}$. The use of channels (channel $\mathrm{A}$ in this study) was connected via a USB connection to the laptop.
The rotational speeds of the input shaft were measured of an optical tachometer DT-2234B with digital memory. The rotational speed of the electric motor, must be variable. By using the dimmer switch voltage of the electric motor is low or high. An experimental platform is shown in Figure 2.

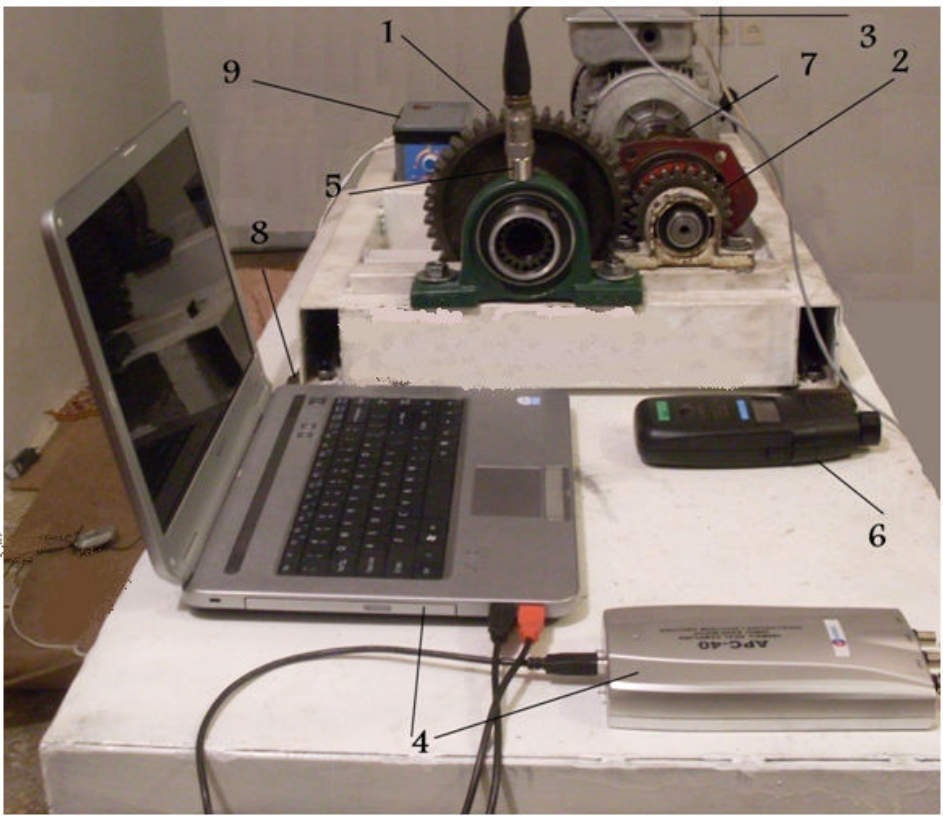

Figure 2. Data capture platform

All the data collected devices are made up following parts (see Figure 2):

1 - Gear, gear shafts

2 - Small gears to transfer power to the main gear.

3 - Single phase Electric motor with $750 \mathrm{~W}$ power

4 - The system data captures APC-40 and laptop

5 - Accelerometer sensor VMI-102

6 - Optical tachometer DT-2234B

7 - Coupling to connect the input and output gear shaft

8 - Vibration absorbing rubbers

9 - Industrial dimmer.

\section{Feature Extraction}

The original data set was divided by the 1024 data points signal. Each of these signals was processed to extract 11 features, ( Mean value, Standard deviation, Root mean square (RMS), Peak value, Shape factor, Impulse factor, Crest factor, Sample standard deviation, Sample variance, Kurtosis, Skewness) in the time domain (T1T11). These 11 features Parameters are shown in Table 1. Frequency domain is another description of the signal. Some of the information is not found in the time domain. To transfer from time domain to the frequency domain was using the FFT phase angle extract 11 features (P1, P11) and the PSD extract 11 features (A1, A11) as shown in Table 1. 
Table 1 . Statistical features in the time and frequency domain

\begin{tabular}{|c|c|c|}
\hline \multirow[b]{2}{*}{ Features in the time domain } & \multicolumn{2}{|l|}{ Features in the frequency domain } \\
\hline & PSD & FFT phase angle \\
\hline $\mathrm{T}_{1}=\frac{\sum_{\mathrm{n}-1}^{\mathrm{N}} \mathrm{x}(\mathrm{n})}{\mathrm{N}}$ & $\mathrm{P}_{1}=\frac{\sum_{\mathrm{k}-1}^{\mathrm{K}} \mathrm{s}(\mathrm{k})}{\mathrm{K}}$ & $A_{1}=\frac{\sum_{j-1}^{J} i(j)}{J}$ \\
\hline $\mathrm{T}_{2}=\sqrt{\frac{\sum_{\mathrm{n}-1}^{\mathrm{N}}\left((\mathrm{x}(\mathrm{n})-\mathrm{T} 1)^{2}\right.}{\mathrm{N}-1}}$ & $\mathrm{P}_{2}=\sqrt{\frac{\sum_{\mathrm{k}-1}^{\mathrm{K}}\left(\left(\mathrm{s}(\mathrm{k})-\mathrm{P}_{1}\right)^{2}\right.}{\mathrm{k}-1}}$ & $A_{2}=\sqrt{\frac{\sum_{j-1}^{J}\left(\left(i(j)-A_{1}\right)^{2}\right.}{J-1}}$ \\
\hline $\begin{aligned} \mathrm{T}_{3} & =\sqrt{\frac{\sum_{\mathrm{n}-1}^{\mathrm{N}}(\mathrm{x}(\mathrm{n}))^{2}}{\mathrm{~N}}} \\
\mathrm{~T}_{4} & =\max |\mathrm{x}(\mathrm{n})|\end{aligned}$ & $\begin{array}{c}\mathrm{P}_{3}=\sqrt{\frac{\sum_{\mathrm{k}-1}^{\mathrm{K}}(\mathrm{s}(\mathrm{k}))^{2}}{\mathrm{~K}}} \\
\mathrm{P}_{4}=\max |\mathrm{s}(\mathrm{k})|\end{array}$ & $\begin{aligned} \mathrm{A}_{3} & =\sqrt{\frac{\sum_{\mathrm{j}-1}^{\mathrm{J}}(\mathrm{i}(\mathrm{j}))^{2}}{\mathrm{~J}}} \\
\mathrm{P}_{4} & =\max |\mathrm{i}(\mathrm{j})|\end{aligned}$ \\
\hline $\begin{array}{c}\mathrm{T}_{5}=\frac{\mathrm{T}_{3}}{\frac{1}{\mathrm{~N}} \sum_{\mathrm{n}-1}^{\mathrm{N}}|\mathrm{x}(\mathrm{n})|} \\
\mathrm{T}_{6}=\frac{\mathrm{T}_{4}}{\frac{1}{\mathrm{~N}} \sum_{\mathrm{n}-1}^{\mathrm{N}}|\mathrm{x}(\mathrm{n})|} \\
\mathrm{T}_{7}=\frac{\mathrm{T}_{4}}{\mathrm{~T}_{3}}\end{array}$ & $\begin{aligned} & \mathrm{P}_{5}= \frac{\mathrm{P}_{3}}{\frac{1}{\mathrm{~K}} \sum_{\mathrm{k}-1}^{\mathrm{K}}|\mathrm{s}(\mathrm{k})|} \\
& \mathrm{P}_{6}= \frac{\mathrm{P}_{4}}{\frac{1}{\mathrm{~K}} \sum_{\mathrm{k}-1}^{\mathrm{K}}|\mathrm{s}(\mathrm{k})|} \\
& \mathrm{P}_{7}=\frac{\mathrm{P}_{4}}{\mathrm{P}_{3}}\end{aligned}$ & $\begin{array}{c}\mathrm{A}_{5}=\frac{\mathrm{A}_{3}}{\frac{1}{\mathrm{~J}} \sum_{\mathrm{j}-1}^{\mathrm{J}}|\mathrm{s}(\mathrm{j})|} \\
\mathrm{A}_{6}=\frac{\mathrm{A}_{4}}{\frac{1}{\mathrm{~J}} \sum_{\mathrm{j}-1}^{\mathrm{J}}|\mathrm{s}(\mathrm{j})|} \\
\mathrm{A}_{7}=\frac{\mathrm{A}_{4}}{\mathrm{~A}_{3}}\end{array}$ \\
\hline $\mathrm{T}_{8}=\sqrt{\frac{\mathrm{n} \sum_{\mathrm{n}-1}^{\mathrm{N}} \mathrm{x}^{2}(\mathrm{n})-\sum_{\mathrm{n}-1}^{\mathrm{N}}(\mathrm{x}(\mathrm{n}))^{2}}{\mathrm{n}(\mathrm{n}-1)}}$ & $\mathrm{P}_{8}=\sqrt{\frac{\mathrm{K} \sum_{\mathrm{k}-1}^{\mathrm{K}} \mathrm{s}^{2}(\mathrm{k})-\sum_{\mathrm{k}-1}^{\mathrm{K}}(\mathrm{s}(\mathrm{k}))^{2}}{\mathrm{k}(\mathrm{k}-1)}}$ & $\mathrm{A}_{8}=\sqrt{\frac{\mathrm{j} \sum_{\mathrm{j}-1}^{\mathrm{J}} \mathrm{i}^{2}(\mathrm{j})-\sum_{\mathrm{j}-1}^{\mathrm{J}}(\mathrm{i}(\mathrm{j}))^{2}}{\mathrm{j}(\mathrm{j}-1)}}$ \\
\hline $\mathrm{T}_{9}=\left(\mathrm{T}_{8}\right)^{2}$ & $\mathrm{P}_{9}=\left(\mathrm{P}_{8}\right)^{2}$ & $A_{9}=\left(A_{8}\right)^{2}$ \\
\hline $\mathrm{T}_{10}=\frac{\sum_{\mathrm{n}-1}^{\mathrm{N}}\left(\mathrm{x}(\mathrm{n})-\mathrm{T}_{1}\right)^{4}}{\mathrm{~N} \times\left(\mathrm{T}_{9}\right)^{2}}$ & $\mathrm{P}_{10}=\frac{\sum_{\mathrm{k}-1}^{\mathrm{K}}\left(\mathrm{s}(\mathrm{k})-\mathrm{P}_{1}\right)^{4}}{\mathrm{~K} \times\left(\mathrm{P}_{9}\right)^{2}}$ & $A_{10}=\frac{\sum_{j-1}^{J}\left(i(j)-A_{1}\right)^{4}}{J \times\left(A_{9}\right)^{2}}$ \\
\hline $\mathrm{T}_{11}=\frac{\mathrm{n}}{(\mathrm{n}-1)(\mathrm{n}-2)} \sum_{\mathrm{n}-1}^{\mathrm{N}}\left(\frac{\mathrm{x}(\mathrm{n})-\mathrm{T}_{1}}{\mathrm{~T}_{8}}\right)^{3}$ & $P_{11}=\frac{k}{(k-1)(k-2)} \sum_{k=1}^{K}\left(\frac{s(k)-P_{1}}{P_{8}}\right)^{3}$ & $A_{11}=\frac{j}{(j-1)(j-2)} \sum_{j-1}^{J}\left(\frac{i(j)-A_{1}}{A_{8}}\right)^{3}$ \\
\hline $\begin{array}{l}\text { where } x(n) \text { is a signal series for } n= \\
1,2, \ldots, N, N \text { is the } \\
\text { Number of data points. }\end{array}$ & $\begin{array}{l}\text { where } \mathrm{s}(\mathrm{k}) \text { is a signal series for } \mathrm{k}= \\
1,2, \ldots, \mathrm{K}, \mathrm{K} \text { is the } \\
\text { Number of data points. }\end{array}$ & $\begin{array}{l}\text { where } i(j) \text { is a signal series for } \mathrm{j}=1,2, \ldots, \mathrm{J} \text {, } \\
\mathrm{J} \text { is the } \\
\text { Number of data points. }\end{array}$ \\
\hline
\end{tabular}

\section{Principal Components Analysis}

Principal component analysis is a mathematical transformation that makes the linear combination of the variables. New variables called principal components. Which shows changes in key variables. (Bastianoni et al., 2008; Sengur, 2008). In fact, pattern PCA provides the first principal component that explains the maximum variance in the original data. The second major component shows most of the remaining variance in the orthogonal data and the like. Principal component can be extracted from each row of data (the covariance matrix) or standardized data (the correlation matrix). Standardization of data causes regardless of the data is same important. Principal component analysis is used as a way to reduce the size of the original data. (Bastianoni et al., 2008; Dubey and Yadava, 2008).
Theoretical procedures for principal component analysis is described by Dubey and Yadava (2008).

\section{ANFIS}

ANFIS is a sugeno fuzzy model that by train of artificial neural network, fuzzy inference system is optimized. Inputs membership functions are mapping through inputs, and then output membership function mapped to the output.

ANFIS structure based fuzzy model with two rules ifthen first order sugeno is described as follows. For brevity and simplicity describe a fuzzy system with two inputs $\mathrm{y}$ and $\mathrm{x}$ and one output $\mathrm{z}$.

Rule 1: if $\left(x\right.$ is $\left.A_{1}\right)$ and $\left(y\right.$ is $\left.b_{1}\right)$ then $\left(z_{1}=p_{1} x+q_{1} y+r_{1}\right)$

Rule 2: if $\left(x\right.$ is $\left.A_{2}\right)$ and $\left(y\right.$ is $\left.b_{2}\right)$ then $\left(z_{2}=p_{2} x+q_{2} y+r_{2}\right)$

$x$ and $y$ inputs and the $A i$ and $B i$ fuzzy rules set and $Z_{1}$ $(i=1,2)$ outputs are determined by the fuzzy rules. Parameters during the training process has been designed. ANFIS structure to handle these two rules is. 


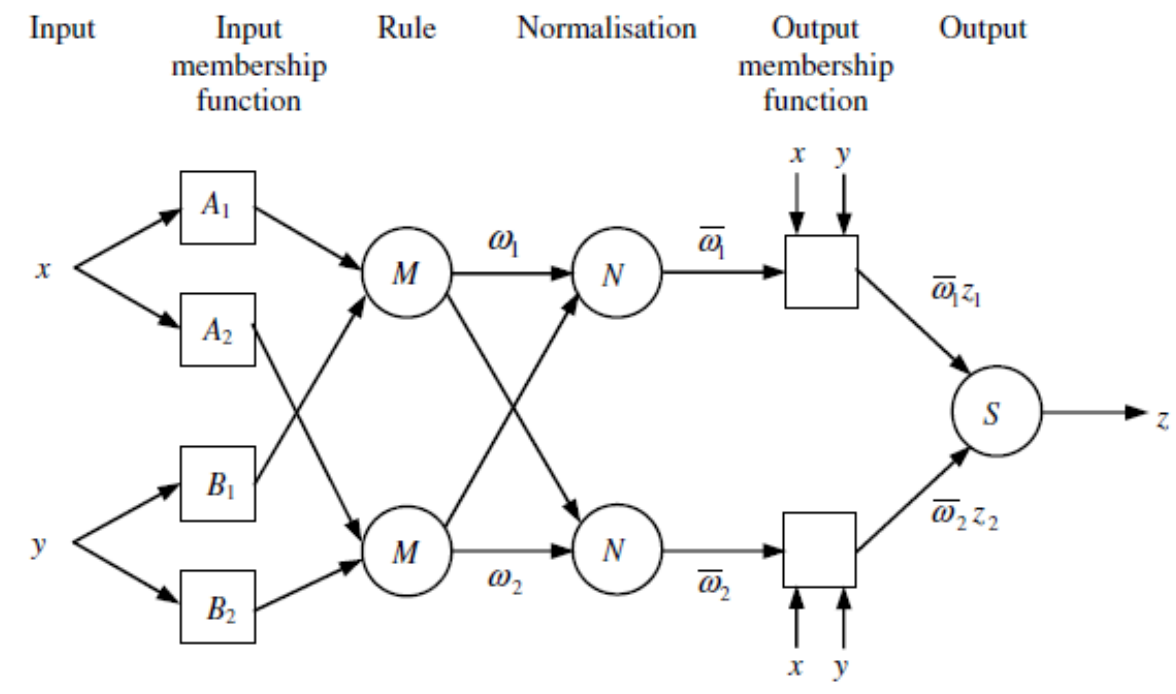

Figure 3. Structure of ANFIS

shown in Figure 3. The circles are shown as fixed nodes while the square indicates an adaptive node Input membership function layer: This layer of the fuzzy input, and all of its nodes are adaptive. The outputs of this layer are graded membership input.

$$
\begin{array}{ll}
0_{1, i}=u_{A_{1}}(\mathrm{x}) & \mathrm{i}=1,2 \\
0_{1, \mathrm{i}}=u_{\mathrm{B}_{\mathrm{i}-2}}(\mathrm{y}) & \mathrm{i}=3,4
\end{array}
$$

Where $u_{A_{1}}(\mathrm{x})$ and $u_{\mathrm{B}_{\mathrm{i}-2}}(\mathrm{y})$ can takes any fuzzy membership function. Usually, a bell-shaped membership function that is used that is shown below.

$$
u_{A, i}=\frac{1}{1+\left[\left(\frac{\mathrm{x}-\mathrm{c}_{\mathrm{i}}}{\mathrm{a}_{\mathrm{i}}}\right)\right]^{\mathrm{b}_{\mathrm{i}}}} \quad \mathrm{i}=1,2
$$

Where $\{$ ai, bi, ci\} are the parameters of the membership function. The bell-shaped functions are monitored rule Layer: All nodes in this layer are fixed nodes. $\mathrm{M}$ are the name of the agency that they have been used as a simple multiplier. The output layer to represent the fuzzy strength of each rule that shown in below.

$$
0_{2, i}=\mathrm{w}_{\mathrm{i}}=u_{\mathrm{A}_{1}}(\mathrm{x}) \times u_{\mathrm{B}_{1}}(\mathrm{y}) \quad \mathrm{i}=1,2
$$

Normalized layers: All nodes in this layer are fixed nodes. That they will $\mathrm{n}$ the markup and have the normal rules for fuzzy stability of the previous layers. Normalization factor is calculated as the sum of all weight functions. The output of this layer can be stated as follows.

$$
0_{3, i}=\overline{w_{i}}=\frac{w_{i}}{w_{1}+w_{2}} \quad i=1,2
$$

The fourth layer output membership function layer, the nodes are adaptive nodes. The output layer as follows.

$$
0_{4, i}=\overline{\mathrm{w}_{\mathrm{i}}} \mathrm{z}_{\mathrm{i}}=\overline{\mathrm{w}_{\mathrm{i}}}\left(\mathrm{p}_{\mathrm{i}} \mathrm{x}+\mathrm{q}_{\mathrm{i}} \mathrm{y}+\mathrm{r}_{\mathrm{i}}\right) \quad \mathrm{i}=1,2
$$

Where $\left\{\mathrm{p}_{\mathrm{i}}, \mathrm{q}_{\mathrm{i}}, \mathrm{r}_{\mathrm{i}}\right\}$ are the output membership function parameters.

Output layer: In this layer, there are only a fixed node is called S. It will tie together all input signals

$$
0_{5, i}=Z=\sum_{i} \overline{\mathrm{w}_{\mathrm{i}}} \mathrm{Z}_{\mathrm{i}}=\frac{\sum_{i} \mathrm{w}_{\mathrm{i}} \mathrm{Z}_{\mathrm{i}}}{\sum_{i} \mathrm{w}_{\mathrm{i}}}
$$

In order to improve the effectiveness of education and the elimination of errors due to local minimum hybrid educational pattern is used to membership function set parameter regulation. This method is the combination of gradient correct method for least squares estimation (Jang, 1993; lei et al., 2008).

\section{RESULTS AND DISCUSSION}

After extracting the 33 features of a data set, variables are analyzed using PCA. After excluding the surplus age features, 13 features are shown in Table 1 are retained and then by the PCA feature reduction to 3 components. These components represent $92 \%$ of the variation as shown in Table 2. One component more indicates the variation of $\mathrm{A}_{2}, \mathrm{~A}_{3}, \mathrm{~A}_{4}, \mathrm{~A}_{6}, \mathrm{~A}_{7}, \mathrm{~A}_{8}, \mathrm{~A}_{9}$, while the second component represents more variations of $\mathrm{T}_{6}, \mathrm{P}_{6}, \mathrm{~T}_{7}$, and P7 and represents the third component represents most variations of $\mathrm{T}_{11}, \mathrm{P}_{11}$. The coefficients matrix of the three components are given in Table 1, too. There are 3 components create by linear combination of the 13 features. 
Table 2. Principal components analysis

\begin{tabular}{lllllll}
\hline & \multicolumn{3}{l}{ Principal component variations } & \multicolumn{3}{l}{ Coefficients of components } \\
\cline { 2 - 7 } & 1 & 2 & 3 & 1 & 2 & 3 \\
\hline $\mathrm{A}_{2}$ & .971 & .017 & .037 & .162 & .013 & .010 \\
$\mathrm{~A}_{3}$ & .984 & .024 & .020 & .165 & .016 & .000 \\
$\mathrm{~A}_{4}$ & .973 & .062 & .027 & .163 & .025 & .000 \\
$\mathrm{~T}_{6}$ & -.034 & .994 & .075 & .005 & .252 & -.043 \\
$\mathrm{P}_{6}$ & -.034 & .994 & .075 & .005 & .252 & -.043 \\
$\mathrm{~A}_{6}$ & -.797 & .183 & .042 & -.131 & .035 & .014 \\
$\mathrm{~T}_{7}$ & -.028 & .991 & .108 & .006 & .248 & -.026 \\
$\mathrm{P}_{7}$ & -.028 & .991 & .108 & .006 & .248 & -.026 \\
$\mathrm{~A}_{7}$ & -.825 & .208 & .023 & -.136 & .042 & .002 \\
$\mathrm{~A}_{8}$ & .971 & .017 & .037 & .162 & .013 & .010 \\
$\mathrm{~A}_{9}$ & .942 & .076 & -.013 & .158 & .032 & -.022 \\
$\mathrm{~T}_{11}$ & .011 & .132 & .991 & -.006 & -.048 & .510 \\
$\mathrm{P}_{11}$ & .011 & .132 & .991 & -.006 & -.048 & .510 \\
\hline
\end{tabular}

Selection of the appropriate input data to classify is the most important steps to increase the accuracy of fault classification. Input data should be correctly distributed to appropriate model is created and which input is important to create the best model. In this study, in order that the benefaction of data distribution for each of speeds the 130 time data acquisition is done. Three different speeds are 1000, 1500 and 2000 RPM. Three components have $92 \%$ of the variations of original data were used for the ability increase of presenting a model to fault prediction at different speeds. Three components are applied as ANFIS input.
The check data increases the validity of the system output data. ANFIS functions adaptive were related to the size of the training data and the check data. In this study, 70 percent for training data and 30 percent of the data was used for verification (check data). The check data sets is applied to generality verify of the fuzzy inference system. The main idea for use of check data sets, about over fitting of the model. It also trains and check data are for generalization of the system in selection of different models. In Table 3, the different membership functions are evaluated for fault detection modelling.

Table 3. Evaluate of different membership functions

\begin{tabular}{lllll}
\hline MF type & R & SSE & MAE & MSE \\
\hline trimmf & 0.999732 & 0.126152 & 0.007971 & 0.000359 \\
trapmf & 0.882101 & 52.34091 & 0.206911 & 0.149119 \\
gbelmf & 0.999997 & 0.001528 & 0.000947 & $4.35 \mathrm{E}-06$ \\
gaussmf & 0.999994 & 0.002791 & 0.001061 & $7.95 \mathrm{E}-06$ \\
gauss2mf & 0.999999 & 0.000181 & 0.000374 & $5.16 \mathrm{E}-07$ \\
primf & 0.913381 & 38.80522 & 0.152724 & 0.110556 \\
dsigmf & 0.999964 & 0.016799 & 0.002029 & $4.79 \mathrm{E}-05$ \\
psigmf & 0.999964 & 0.016799 & 0.002029 & $4.79 \mathrm{E}-05$ \\
\hline
\end{tabular}

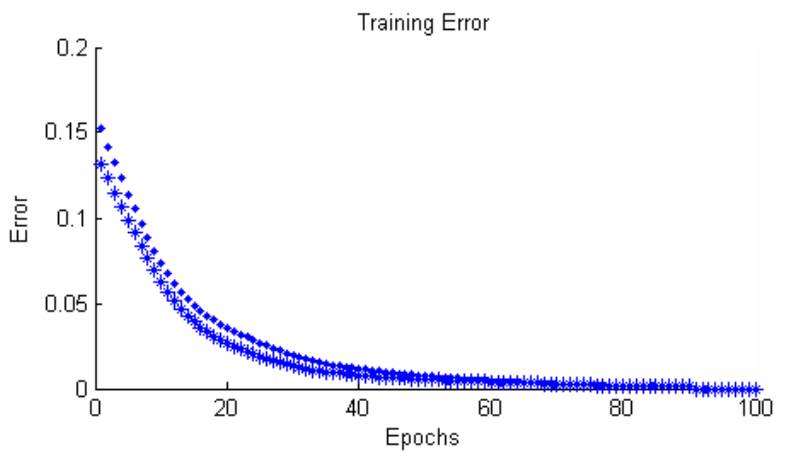

Figure 4. The RMS error curve convergence for gauss $2 \mathrm{mf}$ model 
The model that created by gauss $2 \mathrm{mf}$ membership functions is the best model between different model that created by different membership functions In Figure 4 can be seen training RMSE of checking data (*) and training data $(*)$ for the gauss $2 \mathrm{mf}$ membership functions model.

In order to fault diagnosis number one gear of a tractor Massey Ferguson 285 by ANFIS, the topology structure of ANFIS of the proposed system is shown in Figure 5. This figure shows the structure of fuzzy rules and membership functions during the training process parameters and the system automatically adjusts to the selected membership functions. The MATLAB build ANFIS structure topology with 27 rules and three input data sets was designed for vibration data set. In this topology, the number of nodes in each layer, the number of fuzzy rules and other information is shown.

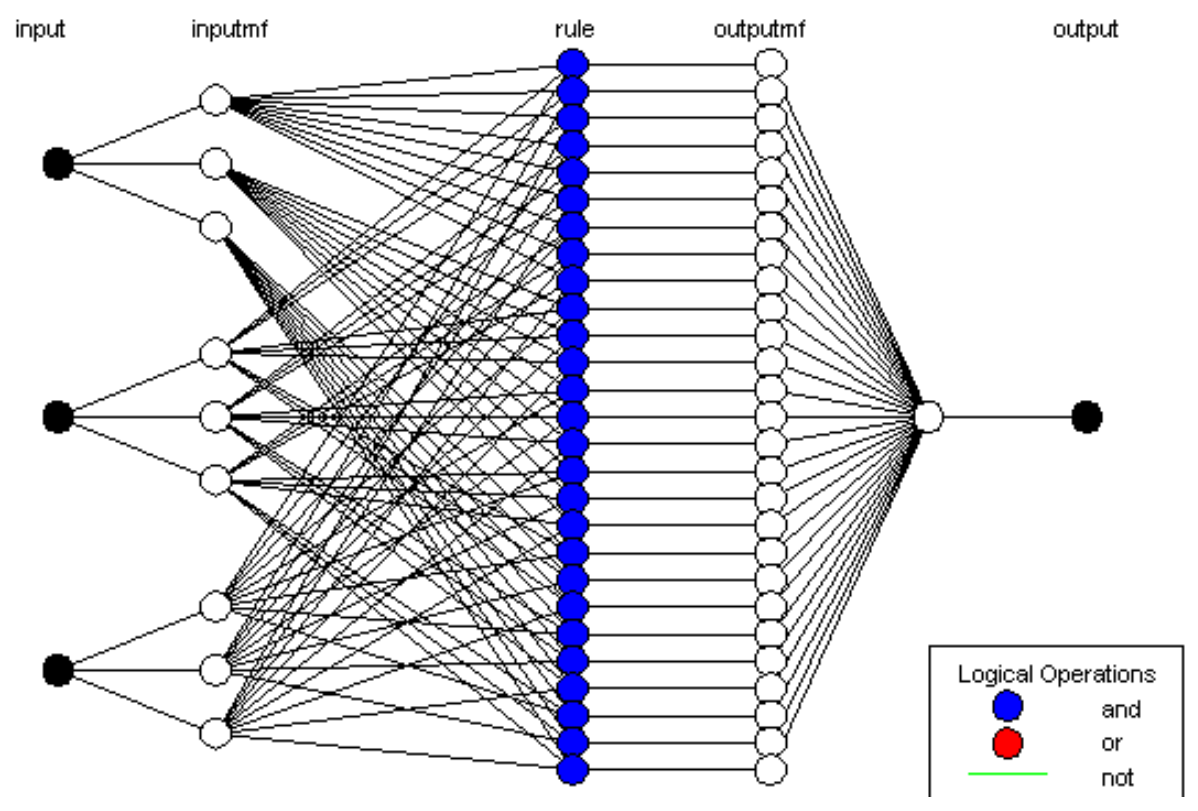

Figure 5. Topology structure of ANFIS

Comparing the experimental and predicted values of output for the model prediction faults by gauss $2 \mathrm{mf}$ is shown in Figure 6. Figure 6 shows the experimental points are marked with stars and the results of the predicted system are marked with circles. In figure 6 shows the output in this study, number 0 is normal mode and the number 1 is gear with wearing tooth and the number 2 is gear with breaking a tooth. The relation between 3 component and output are shown in Figure 7, 8, 9. Between numbers $\{0,2\}$ that show in color bar show reliably predict different fault categories and severities. If the output is close to zero, gear wear is predicted lower and the output is close to two, gear break is predicted upper. The statistical parameters are used to select the best model such as; correlation coefficient (R), sum squared error (SSE), Mean absolute error, (MAE) mean square error (MSE). Where $\mathrm{R}=0.999999$ represents the model with this data set has been able to present the predicts fault severities correctly 


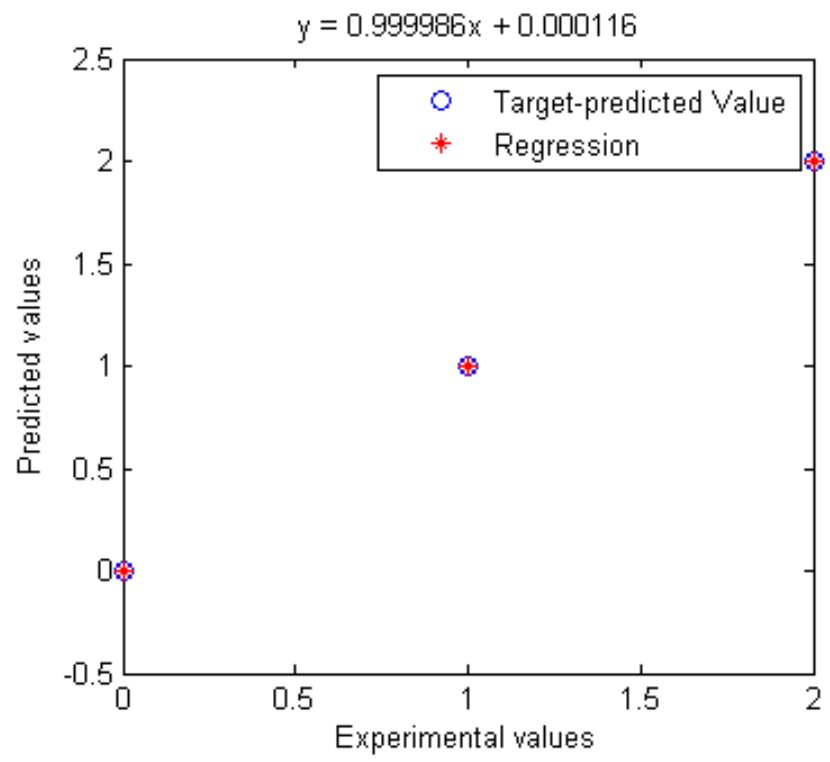

Figure 6. Comparing the experimental output and predicted values

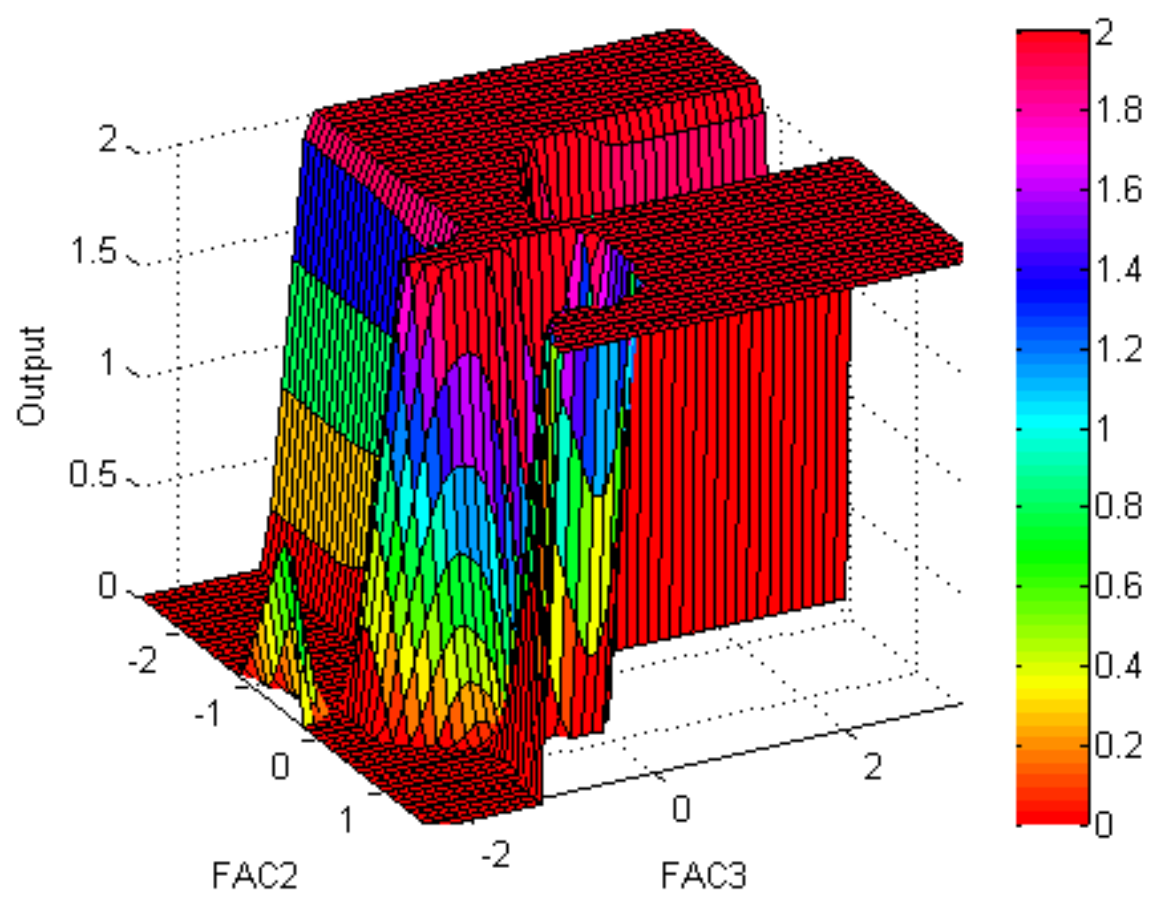

Figure 7. The dependence plot of components 2,3 (FAC2,3) and outputs 


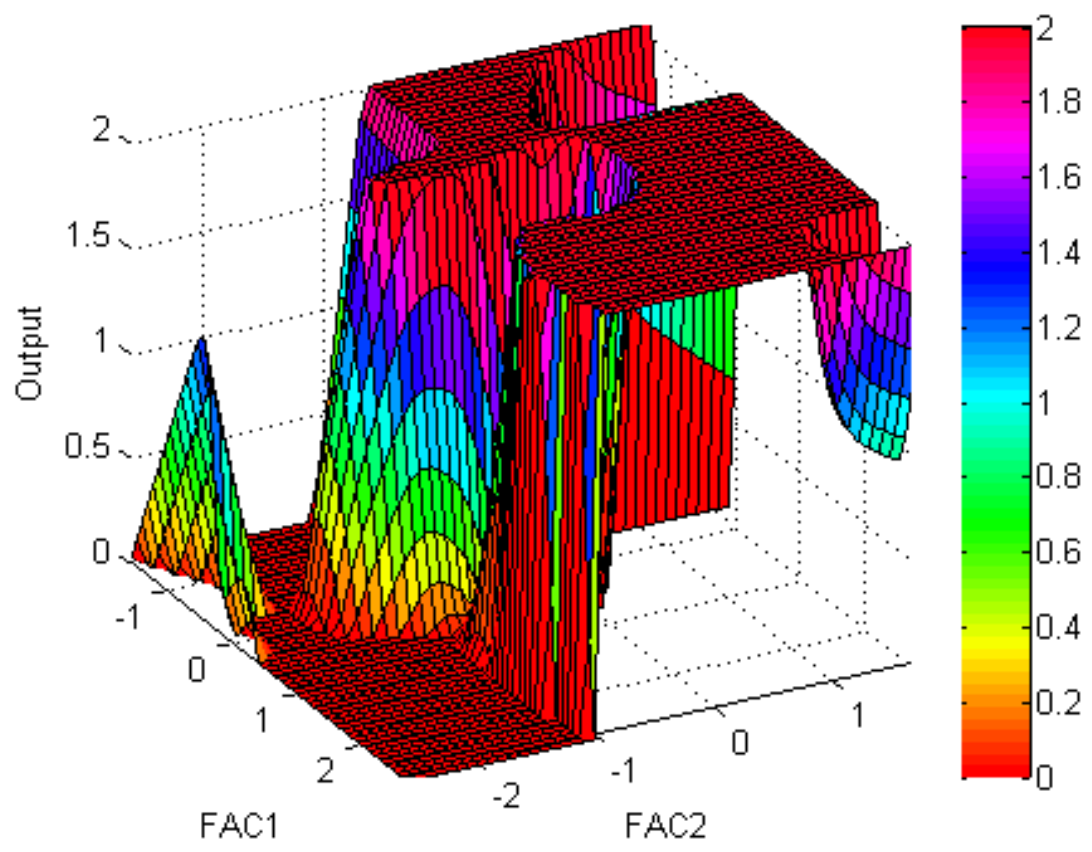

Figure 8. The dependence plot of components 1, 2 (FAC1, 2) and outputs

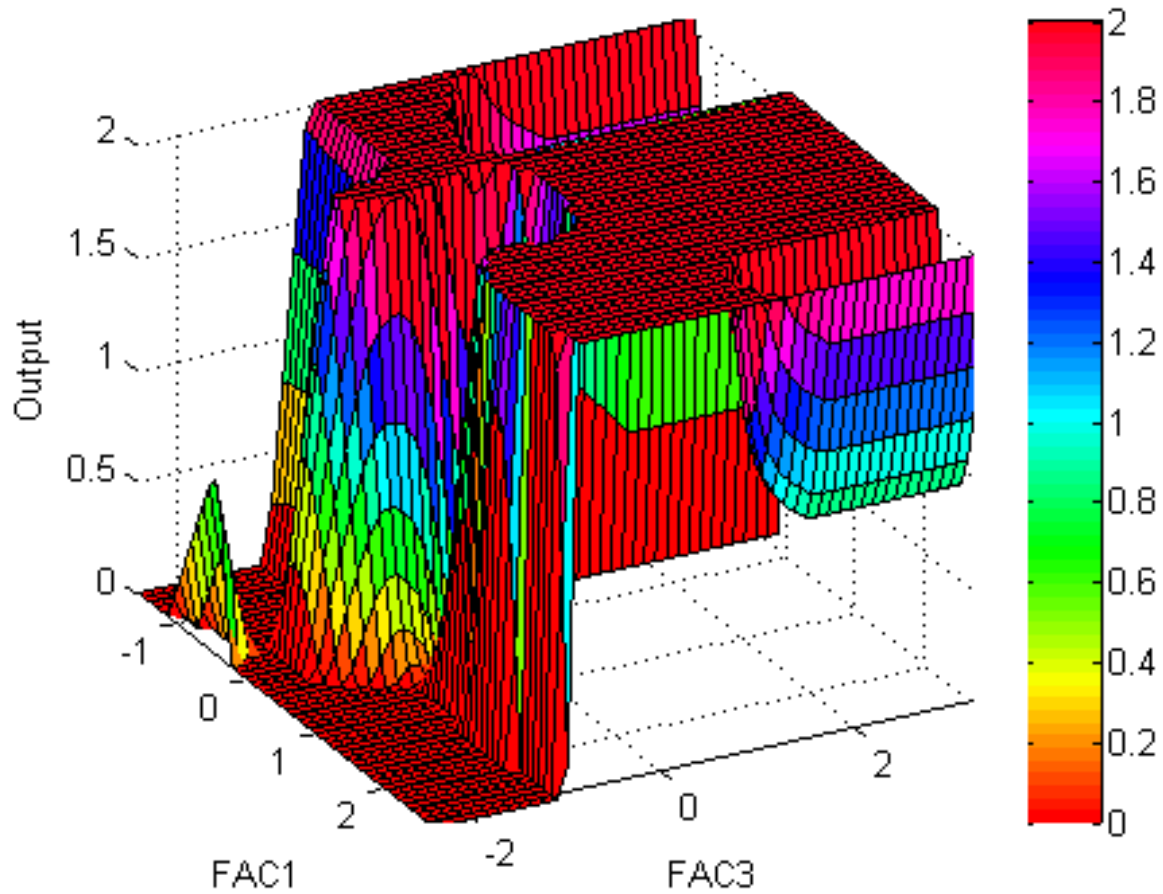

Figure 9. The dependence plot of components 1, 3 (FAC1,3) and outputs

\section{CONCLUSION}

The approach to intelligent fault diagnosis of gearbox number one gears of MF285 tractor based on statistical analysis, Principal component analysis for data reduction and adaptive Neuro-fuzzy inference system (ANFIS), is proposed in this study. Time-domain statistical features, frequency-domain statistical features FFT phase angle and PSD are extracted, respectively, to gain on the great value of faulty information from vibration signals. 
In order to remove the redundant or irrelevant data and reduce data for ANFIS input, a Principal component analysis is introduced and used to take the most superior features, and then used in fault predicting of gearbox number one gear's of MF285 indicates the proposed model can reliably predict different fault is very effective. The model that created by gauss $2 \mathrm{mf}$ membership functions is the best model between different model that created by different membership functions. Formative assessment of prediction models is done through a correlation coefficient (R), sum squared error (SSE), Mean absolute error, (MAE) mean square error (MSE). Where R is $0.999999, \mathrm{SSE}$ is 0.000181 and MSE is 5.16E-07 and MAE is 0.000374 . Here close to R is 1 represents the model with this data set has been able to predict fault severities.

\section{ACKNOWLEDGMENTS}

The authors would like to acknowledge the financial support from Ministry of Science, Research and Technology, Tehran, Iran and the Vice Chancellor for Research and Technology of Razi University of Kermanshah and Kermanshah Branch Islamic Azad University. Also the authors thank Mohamad Hadi Jalili and Nasrolah Astan for technical assistance.

\section{REFERENCES}

1. Adhikari, S., Sinha, N. and Dorendrajit, T., 2016. Fuzzy logic based on-line fault detection and classification in transmission line. SpringerPlus, 5(1), pp.1-14.

2. Ahmed, R., El Sayed, M., Gadsden, S.A., Tjong, J. and Habibi, S., 2015. Automotive internal-combustionengine fault detection and classification using artificial neural network techniques. IEEE Transactions on Vehicular Technology, 64(1), pp.21-33.

3. Ali, J.B., Fnaiech, N., Saidi, L., Chebel-Morello, B. and Fnaiech, F., 2015. Application of empirical mode decomposition and artificial neural network for automatic bearing fault diagnosis based on vibration signals. Applied Acoustics, 89, pp.16-27.

4. Bangalore, P. and Tjernberg, L.B., 2015. An artificial neural network approach for early fault detection of gearbox bearings. IEEE Transactions on Smart Grid, 6(2), pp.980-987.

5. Bastianoni, S., Pulselli, F.M., Focardi, S., Tiezzi, E.B. and Gramatica, P., 2008. Correlations and complementarities in data and methods through Principal Components Analysis (PCA) applied to the results of the SPIn-Eco Project. Journal of environmental management, 86(2), pp.419-426.

6. Dehghani, M., Khooban, M.H. and Niknam, T., 2016. Fast fault detection and classification based on a combination of wavelet singular entropy theory and fuzzy logic in distribution lines in the presence of distributed generations.International Journal of Electrical Power and Energy Systems, 78, pp.455-462.

7. Dubey, A.K. and Yadava, V., 2008. Multi-objective optimization of Nd: YAG laser cutting of nickel-based superalloy sheet using orthogonal array with principal component analysis. Optics and Lasers in Engineering, 46(2), pp.124-132.

8. Ebrahimi, E., Javadikia, P., Astan, N., Heydari, M., Bavandpour, M., Jalili, M.H. and Zarei, A., 2013. Developing an Intelligent Fault Diagnosis of MF285 Tractor Gearbox Using Genetic Algorithm and Vibration Signals. Modern Mechanical Engineering, 3(04), p.152. 9. Halim, E.B., Choudhury, M.S., Shah, S.L. and Zuo, M.J., 2008. Time domain averaging across all scales: A novel method for detection of gearbox faults. Mechanical Systems and Signal Processing, 22(2), pp.261-278.

10. Heidarbeigi, K., Ahmadi, H., Omid, M. and Tabatabaeefar, A., 2010. Evolving an artificial neural network classifier for condition monitoring of massy Ferguson tractor gearbox. International Journal of Applied Engineering Research, 5(12), pp.2097-2107.

11. Jang, J.S., 1993. ANFIS: adaptive-network-based fuzzy inference system. IEEE transactions on systems, man, and cybernetics, 23(3), pp.665-685.

12. Jedliński, Ł. and Jonak, J., 2015. Early fault detection in gearboxes based on support vector machines and multilayer perceptron with a continuous wavelet transform. Applied Soft Computing, 30, pp.636-641.

13. Jia, F., Lei, Y., Lin, J., Zhou, X. and Lu, N., 2016. Deep neural networks: A promising tool for fault characteristic mining and intelligent diagnosis of rotating machinery with massive data. Mechanical Systems and Signal Processing, 72, pp.303-315.

14. Kaplan, K., Kuncan, M. and Ertunç, H.M., 2015, May. Prediction of bearing fault size by using model of adaptive neuro-fuzzy inference system. In 2015 23nd Signal Processing and Communications Applications Conference (SIU) (pp. 1925-1928). IEEE.

15. Lei, Y., He, Z. and Zi, Y., 2008. A new approach to intelligent fault diagnosis of rotating machinery. Expert Systems with Applications, 35(4), pp.1593-1600.

16. Li, Y., Xu, M., Wei, Y. and Huang, W., 2016. A new rolling bearing fault diagnosis method based on multiscale permutation entropy and improved support vector machine based binary tree. Measurement, 77, pp.80-94.

17. Liu, R., Yang, B., Zhang, X., Wang, S. and Chen, X., 2016. Time-frequency atoms-driven support vector machine method for bearings incipient fault diagnosis. Mechanical Systems and Signal Processing, 75, pp.345-370.

18. Lou, X. and Loparo, K.A., 2004. Bearing fault diagnosis based on wavelet transform and fuzzy 
inference. Mechanical systems and signal processing, 18(5), pp.1077-1095.

19. Loutridis, S.J., 2008. Gear failure prediction using multiscale local statistics.Engineering structures, 30(5), pp.1214-1223.

20. Milovančević, M., Nikolić, V. and Anđelković, B., 2016. Analyses of the most influential factors for vibration monitoring of planetary power transmissions in pellet mills by adaptive neuro-fuzzy technique. Mechanical Systems and Signal Processing. 21. Moosavian, A., Khazaee, M., Ahmadi, H., Khazaee, M. and Najafi, G., 2015. Fault diagnosis and classification of water pump using adaptive neuro-fuzzy inference system based on vibration signals. Structural Health Monitoring, 14(5), pp.402-410.

22. Mustafa, M.O., Varagnolo, D., Nikolakopoulos, G. and Gustafsson, T., 2016. Detecting broken rotor bars in induction motors with model-based support vector classifiers. Control Engineering Practice, 52, pp.15-23. 23. Sengur, A., 2008. An expert system based on principal component analysis, artificial immune system and fuzzy k-NN for diagnosis of valvular heart diseases. Computers in Biology and Medicine, 38(3), pp.329-338.
14. Sharma, A., Amarnath, M. and Kankar, P.K., 2016. Feature extraction and fault severity classification in ball bearings. Journal of Vibration and Control, 22(1), pp.176-192.

25. Soualhi, A., Razik, H., Clerc, G. and Doan, D.D., 2014. Prognosis of bearing failures using hidden Markov models and the adaptive neuro-fuzzy inference system. IEEE Transactions on Industrial Electronics, 61(6), pp.2864-2874.

26. Ye, Z., Sadeghian, A. and Wu, B., 2006. Mechanical fault diagnostics for induction motor with variable speed drives using Adaptive Neuro-fuzzy Inference System. Electric Power Systems Research, 76(9), pp.742-752.

27. Yesilyurt, I., 2004. The application of the conditional moments analysis to gearbox fault detection-a comparative study using the spectrogram and scalogram. NDT and E International, 37(4), pp.309-320. 28. Zuo, M.J., Lin, J. and Fan, X., 2005. Feature separation using ICA for a one-dimensional time series and its application in fault detection. Journal of Sound and Vibration, 287(3), pp.614-624. 